\title{
СОСТОЯНИЕ И ПЕРСПЕКТИВЫ НАУЧНО-ТЕХНОЛОГИЧЕСКОГО РАЗВИТИЯ НЕФТЯНОЙ ОТРАСЛИ: МИР И РОССИЯ
}

\author{
(c) 2021 Соснина Валерия Алексеевна \\ студент \\ Сибирский Федеральный Университет, Институт Управления Бизнес-процессами \\ E-mail: lera.sosnina.01@mail.ru \\ (c) 2021 Щеголихина Вероника Ильинична \\ студент \\ Сибирский Федеральный Университет, Институт Управления Бизнес-процессами \\ E-mail: verasheg1234@gmail.com \\ (c) 2021 Мордвинова Татьяна Григорьевна \\ студент \\ Сибирский Федеральный Университет, Институт Управления Бизнес-процессами \\ E-mail: Tanyacds2000@mail.ru
}

Научный руководитель: Зубова Марина Витальевна, кандидат экономических наук, Сибирский федеральный университет, Институт управления бизнес-процессами, Кафедра «Бизнес-информатика и моделирование бизнес-процессов».

Анализ состояния нефтяной отрасли, как одной из наиболее важных в мировой экономике, является ключевой идеей исследования. Проанализированы итоги тяжелого для экономики и энергетики 2020 года: определены объемы запасов, добычи и потребления на предыдущий год. Сделаны выводы о перспективах и основных тенденциях развития данной отрасли как в мире в целом, так и в России, где ключевым фактором в нефтяной отрасли является технологическое развитие, отодвигая объем и качество ресурсной базы.

Ключевые слова: Экономика, нефтегазовая отрасль, нефтяная промышленность, извлекаемые ресурсы

Нефтегазовая промышленность является одной из наиболее крупных, сложных и важных отраслей глобальной экономики. Нефть и газ являются основными природными энергоносителями, а продукты их переработки применяются практически во всех отраслях промышленности (энергетика, транспорт, строительство, химическая отрасль, сельское хозяйство и т.д.). На сегодняшний день нефтегазовая отрасль имеет достаточно нестабильное положение вследствие непостоянства спроса, колебания цен на топливное сырье и других факторов. Тем не менее, нефтегазовая промышленность является одним из важнейших секторов современного общества, поскольку до сих пор выступает основным источником энергии, двигающим мировую экономику.

Говоря в целом о сфере энергетики, по данным British Petroleum, мировой спрос на энергию в 2020 году снизился на 4,5\%, а глобальные выбросы углекислого газа в результате снижения потребления энергии - на 6,3\%. Эти падения огромны по историческим стандартам - самое большое падение спроса на энергию и выбросов углекислого газа со времен Второй мировой войны. Если выбросы углерода сократятся такими же средними темпами, как и в прошлом году, в течение следующих 30 лет глобальные выбросы углерода сократятся примерно на 85\% к 2050 году.

Несмотря на падение общего спроса на электроэнергию, доля производства электроэнергии из возобновляемых источников энергии (ветра, солнца, биоэнергии и геотермальной энергии, за исключением гидроэлектроэнергии) имела самый большой рост за всю историю (358 ТВтч). Этот рост был обусловлен сильным увеличением как ветровой (173 ТВтч), так и солнечной (148 ТВтч) генерации. Соответственно, потребление возобновляемых источников энергии выросло на 9,7\%, увеличив долю возобновляемых источников энергии в энергобалансе до 5,7\% с 5,0\% в 2019 году. 
Проводя анализ состояния нефтегазовой отрасли, необходимо произвести оценку запасов, объемов добычи и потребления углеводородов, а также перспективы и сценарии развития данной отрасли.

Мировые аналитические структуры представляют разрозненные данные касательно общих запасов углеводородного сырья, поскольку учёт ресурсов может производиться на основании различных классификаций. Возьмём за основу статистический обзор мировой энергетики транснациональной нефтегазовой компании British Petroleum.

Мировые доказанные запасы нефти на конец 2020 года составили 1732 млрд. баррелей, что на 2 млрд. баррелей меньше, чем в 2019 году. Глобальное соотношение R/P, т.е. отношение доказанных запасов к добыче, показывает, что за- пасы нефти в 2020 году составили более 50 лет текущей добычи. Следует отметить, что ОПЕК владеет 70,2\% мировых запасов.

Лидерами по запасам являются Венесуэла (17,5\% мировых запасов), за ней следуют Саудовская Аравия (17,2\%) и Канада $(9,7 \%)$. Россия в данном рейтинге занимает шестое место с объемом запасов 107,8 млрд. баррелей. Топ-10 стран по запасам нефти представлен в Таблице 1 .

Отрицательную тенденцию имела мировая добыча нефти, которая упала впервые с 2009 года на 6,6 млн. баррелей в сутки в 2020 году как за счет ОПЕК (-4,3 млн. баррелей в сутки), так и стран, не входящих в ОПЕК (-2,3 млн. баррелей в сутки). Ливия (-920000 баррелей в день) и Саудовская Аравия (-790000 баррелей в день) показали наибольшее падение среди участников ОПЕК, в то время как Россия $(-1,0$ млн. баррелей

Таблица 1. Рейтинг стран по доказанным запасам

\begin{tabular}{|l|c|c|}
\hline \multicolumn{1}{|c|}{ Страна } & Запасы, млрд. баррелей & \% от мировых запасов \\
\hline Венесуэла & 303,8 & 17,5 \\
\hline Саудовская Аравия & 297,5 & 17,2 \\
\hline Канада & 168,1 & 9,7 \\
\hline Иран & 157,8 & 9,1 \\
\hline Ирак & 145,0 & 8,4 \\
\hline Российская Федерация & 107,8 & 6,2 \\
\hline Кувейт & 101,5 & 5,9 \\
\hline ОАЭ & 97,8 & 5,6 \\
\hline США & 68,8 & 4,0 \\
\hline Ливия & 48,4 & 2,8 \\
\hline
\end{tabular}

100000

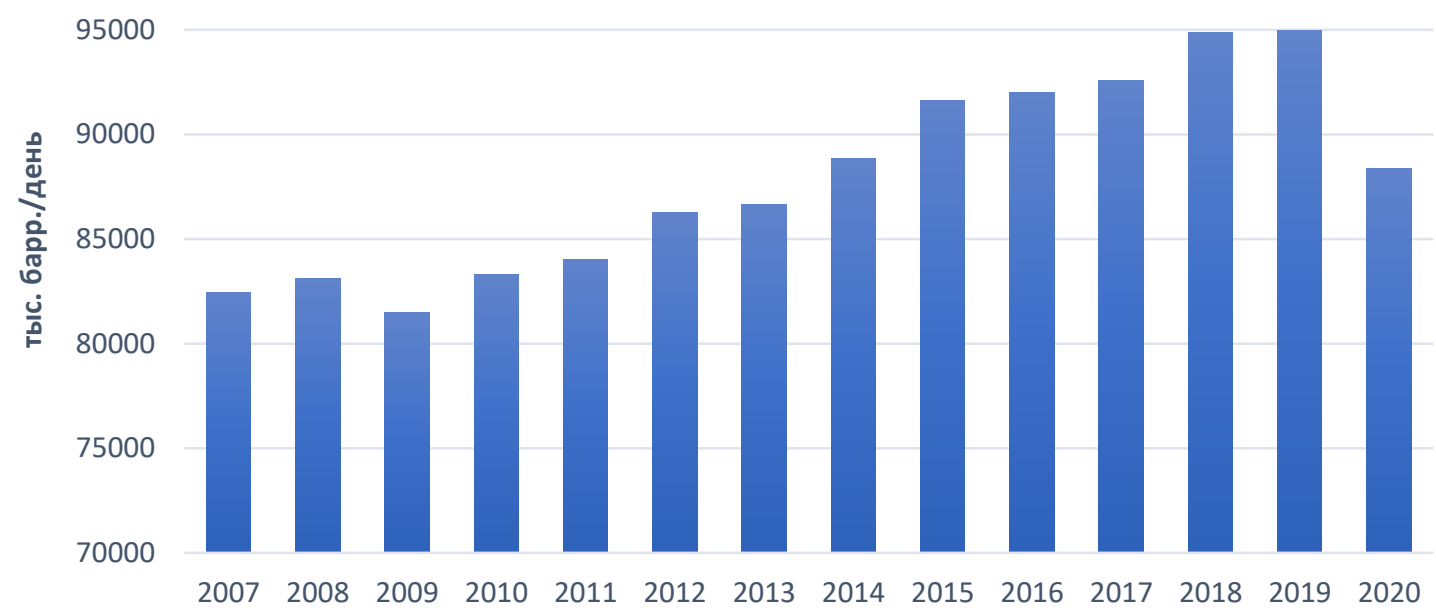

Рисунок 1. Динамика объемов добычи нефти в сутки 
в день) и США (-600000 баррелей в день) лидировали среди стран, не входящих в ОПЕК. Данная динамика продемонстрирована на Рисунке 1.

Добыча увеличилась только в нескольких странах, в основном в Норвегии (260000 баррелей в день) и Бразилии (150000 баррелей в день).

2020 год оказался тяжелейшим вызовом для мирового нефтяного рынка. Пандемия Covid-19 и ограничительные меры в мире привели к беспрецедентному обрушению спроса на нефть. Для недопущения коллапса участники сделки ОПЕК+ смогли договориться о координации своих усилий по стабилизации рынка. За счёт этого удалось избежать избыточного объёма предложения и выйти на относительно приемлемый для нефтедобывающих стран уровень цен.

Завершившийся 2020 г. стал тяжелым и для российской нефтяной отрасли. На фоне вызванного пандемией сокращения спроса на нефть и продукты ее переработки, низкие цены и сокращение доходов нефтяных компаний, работающих в условиях усиливающихся внешних санкций впервые за длительный период ведомственного наблюдения зафиксировано ухудшение всех основных технологических показателей, характеризующих динамику развития нефтяной отрасли и состояние производства в сегменте добычи нефти. При этом ухудшение базовых учетных показателей распространялось на все основные категории недропользователей и регионы российской нефтедобычи.

Объем добычи газа и нефти в России в 2020 году сократился больше, чем в любой другой стране (41 млрд. куб.м. и 1,0 млн. баррелей в сутки соответственно). Сокращение показателей годовой добычи нефти распространяется на все крупнейшие отечественные нефтедобывающие компании, за исключением ПАО «Газпром», добыча нефти которого за рассматриваемый период выросла на 3,3\% к 2019 г. В количественном выражении максимальное сокращение производства фиксируется у крупнейшей нефтедобывающей компании страны ПАО «НК «Роснефть», снизившей добычу нефтяного сырья на $-15,2$ млн. т (-7,8\%) к уровню 2019 года. Наиболее высокие темпы падения производства по сравнению с 2019 г. зафиксированы у компаний ПАО АНК «Башнефть» $(-31,0 \%)$ и ПАО «НГК «Славнефть» $(-30,7 \%)$, снизивших годовой уровень добычи нефти практически на треть.

Анализ отраслевых показателей среднесуточной добычи нефти в течение прошедшего
2020 г. свидетельствует, что пик снижения объемов производства пришелся на летние месяцы (примерно $-17 \%$ к среднесуточным значениям начала года), после чего отраслевая добыча нефти стабилизировалась в коридоре значений 1350-1380 тыс. т / сутки и сохранялась на этом уровне до конца отчетного периода.

В след за добычей сократился и экспорт нефти на 11\%, до 7,3 млн. баррелей в сутки, Россия в настоящее время является третьим по величине экспортером нефти (по сравнению со вторым местом в 2019 году). Европа, за которой следует Китай, выступают основными экспортными нефтяными рынками России.

В 2020 г. суммарный объем вывоза российской нефти с таможенной территории Российской Федерации уменьшился по сравнению с 2019 г. на $-33,7$ млн. т (-12,7\%). Сокращение экспорта осуществлялось по всем основным направлениям поставки. При этом наиболее быстрыми темпами $(-24,4 \%$.) сокращались поставки на объекты переработки стран Ближнего зарубежья. Объем экспорта в страны дальнего зарубежья уменьшился за 2020 г. на $-11,8 \%$. Снижение объемов экспорта в страны дальнего зарубежья происходило в первую очередь за счет сокращения поставок на традиционный для России европейский рынок сбыта. Объем экспорта российской нефти на европейском (западном) направлении, включая Белоруссию, снизился за 2020 г. по сравнению с предшествующим аналогичным периодом на $-19,8 \%$.

Кроме того, произошло уменьшение и экспорта газа на 8,7\%, до 238 млрд. куб.м. Экспорт СПГ увеличился на 3,1\% до 40 млрд. куб. м, а экспорт по трубопроводам сократился на $11 \%$, до 198 млрд. куб. м. Крупнейшими импортерами российского газа являются Германия и Великобритания.

Сложившаяся на сегодняшний день ситуация в нефтяной отрасли России заключается в том, что даже поддержание текущего уровня добычи нефти не представляется возможным без применения высоких технологий в следствие того, что снижается средний дебит вводимых скважин в Западной Сибири, существенно увеличивается их обводненность. Чтобы компенсировать данное снижение добычи, компаниям приходится постоянно наращивать фонд эксплуатационных скважин и, соответственно, увеличивать их глубину.

Таким образом, в общем виде можно вы- 
делить три основных направления научнотехнологического развития отрасли:

1) технологии, увеличивающие коэффициент извлечения нефти, содействующие поддержанию или, возможно, восстановлению рентабельной добычи на существующих месторождениях;

2) технологии добычи нефти нетрадиционных месторождений и нетрадиционной нефти (тяжелая, высоковязкая и сверхвязкая нефть; нефтяные пески и битумы и другие трудноизвлекаемые запасы);

3) технологии добычи нефти на шельфовых месторождениях.

В долгосрочной перспективе добыча тяжелой и вязкой нефти может стать одним из приоритетных направлений, так как имеются огромные запасы данных ресурсов. Особую сложность представляет переработка высоковязкой нефти в связи с отсутствием необходимых технологий и мощностей, а основные экспортные потребители не готовы перерабатывать такую нефть.

В 2020 году мировая торговля нефтью сократилась на 5,3 млн. баррелей в сутки (7,6\%). Большая часть этого снижения пришлась на торговлю сырой нефтью (3,3 млн. баррелей в сутки) и была сосредоточена в Европе (1,6 млн. баррелей в сутки) и США (920000 баррелей в сутки). В Китае, благодаря быстрому экономическому восстановлению после пандемии, импорт сырой нефти увеличился на 970000 баррелей в сутки.

Из-за блокировок и других ограничений, связанных с коронавирусом, торговля нефтепродуктами сократилась на 2,1 миллиона баррелей в сутки. Это было сосредоточено в Европе (620000 баррелей в сутки) и США (360000 баррелей в сутки), что отражает сокращение воздушных и автомобильных перевозок, и ключевом торговом центре Сингапура (325000 баррелей в сутки).

Кроме того, следует отметить, что цена нефти Brent в среднем составила 41,84 доллара за баррель в 2020 году - это самый низкий показатель с 2004 года.

Потребление первичной энергии снизилось на 4,5\% в прошлом году, что стало первым снижением потребления энергии с 2009 года. Снижение произошло в основном за счет сокращения потребления нефти $(-9,7 \%)$, на долю которой пришлось почти три четверти снижения. Динамика объемов потребления нефти за последние 10 лет представлена на Рисунке 2.

Крупнейшими мировыми потребителями нефти в 2020 году выступали США, Китай, Индия, Саудовская Аравия и Япония. Россия занимает шестое место в данном рейтинге, уступая Японии лишь 2,7 млн.т.

Нефть по-прежнему занимает наибольшую долю в энергобалансе (31,2\%). Доля природного газа и возобновляемых источников энергии выросла до рекордно высоких показателей - 24,7\% и 5,7\% соответственно.

Нефть остается доминирующим топливом в Африке, Европе и Америке, в то время как природный газ доминирует в СНГ и на Ближнем Востоке, на долю которого приходится более половины энергетического баланса в обоих регионах.

Природный газ обладает гораздо большей устойчивостью, чем уголь, но потребление газа

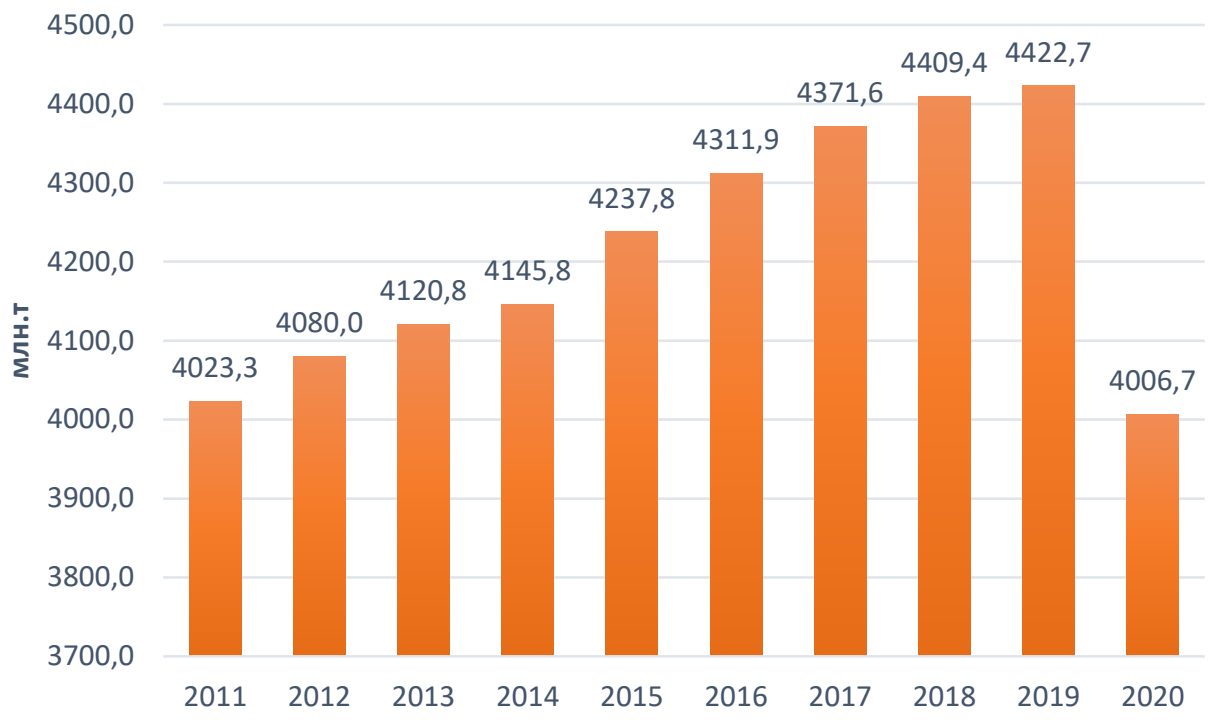

Рисунок 2. Динамика объёмов потребления нефти 
сократилось на 2,3\%, или на 81 млрд. куб. м, аналогично падению, наблюдаемому в 2009 году во время финансового кризиса. Потребление газа снизилось в большинстве регионов - в Северной Америке и Европе на 2,6\% и 2,5\% соответственно. Заметными исключениями из этой тенденции были Китай, где спрос вырос на 6,9\%, и Иран.

Несмотря на снижение абсолютных уровней спроса на газ, доля газа в первичной энергии продолжала расти (из-за общего падения спроса на первичную энергию), достигнув рекордного уровня в $24,7 \%$.

В энергетическом секторе низкие цены на газ помогли производству электроэнергии, работающей на газе, увеличить свою долю в США и закрепиться в Европе.

Что касается перспектив развития всей энергетической отрасли, то следует рассмотреть сценарии, предложенные Британской компанией ВР. Сценарии не являются прогнозами того, что может произойти или чего хотела бы ВР. Скорее, они помогают проиллюстрировать диапазон возможных результатов в течение следующих тридцати лет, хотя неопределенность существенна и сценарии не дают всеобъемлющего описания всех возможных исходов.

Сценарий быстрого перехода (Rapid) предусматривает ряд политических мер, ведущих к значительному росту углеродного налога и поддерживаемых более целевыми отраслевыми мерами, которые приведут к сокращению выбросов углерода примерно на 70\% к 2050 году.

Сценарий полного отказа (Net Zero) предполагает, что политические меры, воплощенные в Rapid, дополняются и усиливаются значительными изменениями в поведении и предпочтениях общества, которые еще больше сократит углеродный след человечества. Глобальные выбросы углерода в результате использования энергии сократятся более чем на 95\% к 2050 году.

Сценарий «Бизнес как обычно» (Business As Usual) предполагает, что государственная политика, технологии и социальные предпочтения продолжают развиваться таким образом и с такой скоростью, как это наблюдалось в недавнем прошлом. Продолжение этого прогресса, хотя и относительно медленное, означает пик выбросов углерода в середине 2020-х годов. Несмотря на этот пик, достигнут незначительный прогресс в плане сокращения выбросов углекислого газа в результате использования энергии, при этом выбросы в 2050 году будут менее чем на
10\% ниже уровня 2018 года.

Спрос на первичную энергию увеличивается примерно на 10\% в Rapid и Net Zero по сравнению с прогнозом и примерно на 25\% в Business As Usual.

Кроме того, энергетический прогноз предлагает следующие ключевые идеи.

Глобальный спрос на энергию продолжит расти, по крайней мере в течение определенного периода, что обусловлено ростом благосостояния и уровня жизни в развивающемся мире. Сохраняется значительное неравенство в потреблении энергии и доступе к ней.

Структура спроса на энергию, вероятно, со временем изменится: снизится роль ископаемого топлива, компенсируемая увеличением доли возобновляемых источников энергии и растущей ролью электроэнергии. Эти изменения лежат в основе основных представлений о том, как может измениться структура спроса на энергию.

Переход к низкоуглеродной энергетической системе, вероятно, приведет к фундаментальной реструктуризации глобальной энергетической системы с более разнообразным сочетанием энергоносителей, более локализованными энергетическими рынками и повышением уровня интеграции и конкуренции. Эти изменения лежат в основе основных представлений о том, как глобальная энергетическая система может перестроиться в условиях низкоуглеродного перехода.

Спрос на нефть будет падать в течение следующих 30 лет. Масштабы и темпы этого снижения обусловлены повышением эффективности и электрификацией автомобильного транспорта.

Перспективы для природного газа более устойчивы, чем для нефти, что подкрепляется ролью природного газа в поддержке быстрорастущих развивающихся экономик, поскольку они обезуглероживаются и сокращают свою зависимость от угля.

Возобновляемые источники энергии, во главе с ветровой и солнечной энергией, являются самым быстрорастущим источником энергии в течение следующих 30 лет, чему способствует значительное увеличение объемов разработки и инвестиций в новые ветровые и солнечные мощности.

Значение электроэнергии в конечном потреблении энергии существенно возрастет в течение следующих 30 лет. Углеродоемкость производства электроэнергии заметно снижается, что обусловлено увеличением доли возобновляемых 
источников энергии по сравнению с углем.

Таким образом, исходя из данных энергетических прогнозов, можем сделать вывод, что будет происходить постепенное увеличение доли возобновляемых источников энергии в энергобалансе, но несмотря на это, ближайшие несколько десятилетий нефть и газ будут оставаться основными энергоносителями в мире. В первую очередь потому, что основной потребитель нефти - это транспорт, и электрокары не смогут потеснить бензиновый мотор в ближайшие годы.

Тем не менее, тренд автомобилизации общества в настоящее время поддерживается, главным образом, за счет расширения автомобильных рынков развивающихся стран, в то время как в развитых странах процесс насыщения общества автомобильной техникой близок к завершению.

В России прогнозируется относительно низкий как экономический, так и демографический рост, что свидетельствует о невысоком внутреннем спросе на моторное топливо. Кроме того, более эффективный природный газ будет вытеснять топочный мазут, а бензин будет конкурировать с газомоторным топливом за спрос. Также развитие использования моторных топлив более высоких экологических классов будет спровоцировано ужесточением природоохранных стандартов.

Россия обладает большими возможностями для развития возобновляемых источников энергии и не останется в стороне от мировой тенденции развития автономной энергетики. Но если российское энергомашиностроение не будет к этому готово, то рыночный сегмент ВИЭ в стране окажется полностью занят иностранными производителями, работающими по своим стандартам.

Таким образом, можно сделать вывод, что, в связи с течением времени и многочисленными изменениями в нефтегазовой отрасли, на первый план, среди ключевых факторов, определяющих развитие, выходят технологии, отодвигая объем и качество ресурсной базы как таковой. Причем технологическое развитие стало признаком не только крупных транснациональных компаний, но и мелких локальных компаний, имеющих доступ к соответствующему технологическому инструментарию. Этот сдвиг будет оказывать решающее влияние на предложение на рынках углеводородов и станет главным фактором ужесточения конкуренции на этих рынках.

В этом отношении российские нефтегазовые компании окажутся подвержены высоким рискам, если их стратегии развития будут определяться не ориентацией на достижение технологического совершенства, а монопольным доступом к ресурсной базе в сочетании с ограниченным числом крупных проектов, чьи высокие издержки покрываются только в случае благоприятной ценовой среды на мировых рынках энергоносителей.

\section{Библиографический список}

1. Ларченко Л.В. Нефтегазовая отрасль России: современное состояние и направления развития в условиях неопределенности / Л. В. Ларченко // Общество. Среда. Развитие (Terra Humana). - 2019.- № 1. [Электронный ресурс] URL: https://cyberleninka.ru/article/n/neftegazovaya-otrasl-rossii-sovremennoe-sostoyanie-inapravleniya-razvitiya-v-usloviyah-neopredelennosti (дата обращения: 02.09.2021).

2. Манукян M.M. Тенденции развития нефтяной промышленности в мировой экономике / М. М. Манукян // Вестник Самарского университета. Экономика и управление. - 2018. - № 1 [Электронный pecypc] URL: https://cyberleninka.ru/article/n/tendentsii-razvitiya-neftyanoy-promyshlennosti-v-mirovoy-ekonomike (дата обращения: 05.09.2021).

3. Обзор нефтегазовой отрасли [Электронный ресурс] URL: https://www.rosneft.ru/docs/report/2020/ru/marketoverview/oil-gas-industry.html\#russian-oil-industry (дата обращения: 01.10.2021).

4. Плешкова Ю.В., Петрова С. В., Карпович Ю. В. Проблемы и перспективы развития нефтегазового комплекса России на современном этапе // Интернет-журнал «Отходы и ресурсы», 2019 № 3, https://resources.today/ PDF/01ECOR319.pdf (дата обращения: 08.09.2021).

5. Прогноз научно-технологического развития отраслей ТЭК [Электронный ресурс] URL: https://minenergo. gov.ru/node/6366 (дата обращения: 05.09.2021)

6. Эволюция мировых энергетических рынков и ее последствия для России / под ред. А.А. Макарова, Л. М. Григорьева, Т.А. Митровой.-М. ИНЭИ РАН-АЦ при Правительстве РФ, 2015.- 400 с

7. British Petroleum [Электронный ресурc] URL: https://www.bp.com/ (дата обращения: 06.09.2021)

8. Statistical Review of World Energy [Электронный ресурс] URL: https://www.bp.com/en/global/corporate/energyeconomics/energy-outlook/introduction/executive-summary.html (дата обращения: 07.09.2021) 